\title{
Dysphagia Care Across the Continuum: A Multidisciplinary Dysphagia Research Society Taskforce Report of Service-Delivery During the COVID-19 Global Pandemic
}

\author{
Anna Miles ${ }^{1,15}$ - Nadine P. Connor ${ }^{2} \cdot$ Rinki Varindani Desai $^{3} \cdot$ Sudarshan Jadcherla ${ }^{4}$ Jacqui Allen ${ }^{1}$. \\ Martin Brodsky ${ }^{5} \cdot$ Kendrea L. Garand ${ }^{6} \cdot$ Georgia A. Malandraki ${ }^{7}$. Timothy M. McCulloch ${ }^{8} \cdot$ Marc Moss $^{9}$. \\ Joseph Murray ${ }^{10}$ - Michael Pulia ${ }^{11}$ - Luis F. Riquelme ${ }^{12,13}$. Susan E. Langmore ${ }^{14}$
}

Received: 8 June 2020 / Accepted: 3 July 2020 / Published online: 11 July 2020

๑) Springer Science+Business Media, LLC, part of Springer Nature 2020

\begin{abstract}
At the time of writing this paper, there are over 11 million reported cases of COVID-19 worldwide. Health professionals involved in dysphagia care are impacted by the COVID-19 pandemic in their day-to-day practices. Otolaryngologists, gastroenterologists, rehabilitation specialists, and speech-language pathologists are subject to virus exposure due to their proximity to the aerodigestive tract and reliance on aerosol-generating procedures in swallow assessments and interventions. Across the globe, professional societies and specialty associations are issuing recommendations about which procedures to use, when to use them, and how to reduce the risk of COVID-19 transmission during their use. Balancing safety for self, patients, and the public while maintaining adequate evidence-based dysphagia practices has become a significant challenge. This paper provides current evidence on COVID-19 transmission during commonly used dysphagia practices and provides recommendations for protection while conducting these procedures. The paper summarizes current understanding of dysphagia in patients with COVID-19 and draws on evidence for dysphagia interventions that can be provided without in-person consults and close proximity procedures including dysphagia screening and telehealth.
\end{abstract}

Keywords Deglutition · Deglutition disorders · Swallowing · Dysphagia · COVID-19 · AGPs

Anna Miles

a.miles@auckland.ac.nz

The University of Auckland, Auckland, New Zealand

2 Communication Sciences \& Disorders; Otolaryngology, Head and Neck Surgery, University of Wisconsin-Madison, Madison, USA

3 Department of Otolaryngology - Head and Neck Surgery, University of Mississippi Medical Center, Jackson, MS, USA

4 Nationwide Children's Hospital and The Ohio State University College of Medicine, Columbus, OH, USA

5 Outcomes After Critical Illness and Surgery (OACIS) Research Group, Division of Pulmonary and Critical Care Medicine, Department of Physical Medicine \& Rehabilitation, Johns Hopkins University, Baltimore, MD, USA

6 Department of Speech Pathology and Audiology, University of South Alabama, Mobile, AL, USA

7 Speech, Language, and Hearing Sciences, and Weldon School of Biomedical Engineering, Purdue University, West Lafayette, IN, USA
8 Otolaryngology, Head and Neck Surgery, University of Wisconsin School of Medicine and Public Health, Madison, USA

9 Division of Pulmonary Sciences and Critical Care Medicine, University of Colorado School of Medicine, Aurora, CO, USA

10 Audiology Speech Pathology Service, VA Ann Arbor Healthcare System, Ann Arbor, MI, USA

11 Emergency Care for Infectious Diseases (ECID) Research Program, BerbeeWalsh Department of Emergency Medicine, University of Wisconsin School of Medicine and Public Health, Madison, USA

12 New York Medical College, Valhalla, NY, USA

13 Barrique Speech-Language Pathology, PC, Brooklyn, NY, USA

14 Otolaryngology Head/Neck Surgery, Boston University School of Medicine, Boston, USA

15 Speech Science, School of Psychology, The University of Auckland, Grafton Campus, Private Bag 92019, Auckland, New Zealand 


\section{Introduction}

Severe acute respiratory syndrome coronavirus 2 (SARS$\mathrm{CoV}-2$ ) is the novel respiratory pathogen responsible for the coronavirus disease 2019 (COVID-19). At the time of writing this paper, there are over 11 million reported cases of COVID-19 and approximately 550,000 associated deaths worldwide [1]. Among its many effects, this global pandemic has led to orders for physical distancing (e.g., stay-at-home orders) and face mask utilization, paused activity within economic spheres, and tremendous strain on healthcare systems [2]. With limited preparation, healthcare practitioners have been tasked with caring for patients with COVID-19 in an environment often lacking in sufficient supplies and personal protective equipment (PPE) [2].

COVID-19 had its origin in Wuhan, China in late 2019 and quickly spread throughout China and then the rest of the world. Patients with COVID-19 have a wide range of clinical severity with hallmarks symptoms of cough, fever, dyspnea, sore throat, muscle pain, headache, fatigue, and loss of taste or smell [3]. For some, symptoms are much more severe including acute respiratory distress syndrome requiring prolonged intubation, severe muscle weakness, dysphagia, cognitive deficits, thrombosis, cerebrovascular events, encephalopathy and multi-organ failure [4-8]. For others, the disease is asymptomatic, and thus, people are unaware that they are carriers of the disease which they can spread to others $[9,10]$.

Containment of virus spread has been a primary focus in healthcare settings. COVID-19 is highly contagious [11] and can be aerosolized by coughing, sneezing, singing, loud speaking and by aerosol-generating procedures (AGPs) [12]. SARS-CoV-2 is viable for hours after it leaves the body. In controlled experiments, SARS-CoV-2 was detected on a variety of surface materials for up to $72 \mathrm{~h}$, with a median half-life of $5.6 \mathrm{~h}$ on stainless steel and $6.8 \mathrm{~h}$ on plastic [13]. Multiple infection control guidelines have been issued to reduce exposure risk within facilities [3].

Procedures for dysphagia assessment and treatment across disciplines must be performed safely. Otolaryngologists, gastroenterologists, pulmonologists, respiratory therapists, rehabilitation specialists, nurses and speech-language pathologists (SLPs) may be subject to COVID-19 exposure due to work performed in proximity to the aerodigestive tract and reliance on AGPs in day-to-day practices. The purpose of this paper is to provide: (1) a review of the current evidence of COVID-19 transmission with a focus on common dysphagia related diagnostic and therapeutic procedures, and (2) a review of multidisciplinary dysphagia care activities across the lifespan that can be conducted with physical distancing including dysphagia screening and telehealth.

\section{Viral Transmission}

Although routes of transmission vary by pathogen, respiratory viruses (e.g., seasonal influenza, common cold, SARSCoV-2) are most commonly spread via direct exposure to cough or sneeze-induced infectious respiratory droplets or contact with contaminated surfaces (fomites) [12, 13]. Airborne transmission refers to infection resulting from inhalation of smaller, pathogen-laden particles that can occur without direct contact or proximity to the source. Critically, pathogens capable of airborne transmission are small enough to pass through or around the edges of a standard surgical mask [14]. Aerosols, defined as collections of particles suspended in a gas, are increasingly recognized as a vector for both droplet and airborne transmission [12, 15]. The difference between respiratory droplet spread and aerosolization is the size of the particles produced and, therefore, the ability for such particles to be deposited within the upper and lower airways and then carried further distally into the respiratory system. Droplets generated by cough vary in size, with larger particles at $>4 \mu \mathrm{m}$ settling rapidly, thereby reducing the amount arriving in the lower respiratory tract [16]. Loss of infectivity within $15 \mathrm{~min}$ after a cough is estimated to be near $90 \%$ even at low RH [16]. In contrast, particles of $<1 \mu \mathrm{m}$ are aerosolized and remain viable for hours within room air with approximately $32 \%$ loss of infectivity within $15 \mathrm{~min}$ [16]. These aerosols can remain viable in the atmosphere for hours and result in delayed exposure.

Disease transmission via droplet transmission from close contact has been well established [17]. It is also well established that normal bodily processes, including speaking and breathing, and those related to respiratory tract infections (e.g., coughing and sneezing) are capable of generating varying amounts of infectious aerosols [12]. Interestingly, some studies have found speaking alone produces a similar number of emission droplets as coughing, with one study estimating that the total number of droplets expelled ranged from 947 to 2085 per cough, 112-6720 for speaking, and lasted 8-14 min in stagnant air [18]. Increased loudness yields larger quantities of droplets than speaking quietly [19]. This is particularly important to the work of SLPs and otolaryngologists, who regularly ask patients to vocalize and cough while visualizing the oral cavity and upper airway at close proximity.

\section{Aerosol-Generating Procedures}

Medical aerosols, such as those generated by nebulization of medication, can exposure healthcare workers to the medication itself and are a vector for respiratory virus transmission when viable pathogens are present within the particles $[11,20]$.The 
amount, distribution, duration and contents of medical aerosols are influenced by multiple variables, including the patient's condition (e.g., viral load), device interface, flow rate, room dimensions, air turbulence, room temperature and particle size. Understanding the likelihood of viable pathogens in aerosols enables sensible decisions on risk versus benefit of therapy and on which PPE should be used in each setting.

Aerosol-generating procedures (AGPs) are those that routinely result in particalized respiratory tract secretions. These medical procedures are of particular concern given their potential to generate high concentrations of infectious respiratory aerosols, thus increasing the risk of airborne pathogen transmission to healthcare providers [3, 15, 21, 22]. The magnitude of transmission risk is related to the density of aerosolized particles generated (concentration), proximity to the airway, and duration of exposure $[11,23]$. According to the Centers for Disease Control and Prevention (CDC), procedures commonly recognized as AGPs include: open suctioning of airway secretions, sputum induction, cardiopulmonary resuscitation, endotracheal intubation and extubation, non-invasive positive pressure ventilation, bronchoscopy, and manual ventilation prior to intubation [3] (Table 1). A review of reported AGPs associated with increased transmission of severe acute respiratory syndrome-1 (SARS-1) coronavirus concluded that these procedures all carried increased risk of viral transmission (odds ratios: 2.3-6.6) [15].

Although not defined as AGPs, interventions related to dysphagia assessment and treatment may provoke behaviors, such as sneezing and coughing. These include clinical (bedside) evaluations, laryngoscopy, transnasal endoscopy (TNE), pharyngeal-esophageal manometry, combined esophageal multichannel intraluminal impedance and $\mathrm{pH}$ monitoring, flexible endoscopic evaluation of swallowing (FEES), modified barium swallow/videofluoroscopic swallowing study, and respiratory muscle strength training procedures. As such, providers are exposed to secretions and/ or aerosols from the nose and nasopharynx which contain high concentrations of SARS-CoV-2 in the early stages of the disease [24-26] (Table 1). Additionally, these procedures differ significantly from routine clinical assessments in terms of exposure risk due to the following factors: (1) inability for patients to wear masks or face coverings, due to the necessity for oropharyngeal examination or oral intake; (2) requirement of close proximity to the airway; and (3) prolonged duration of exposure [23]. As a result of their potential as AGPs and involving direct, proximal, and prolonged exposure to the airway, these procedures have been determined by professional societies worldwide, to be high-risk

Table 1 List of procedures used in multidisciplinary dysphagia care with expert consensus on stratification of risk for COVID-19 transmission

\begin{tabular}{|c|c|c|}
\hline Procedure & Risk(s) & $\begin{array}{l}\text { Level of } \\
\text { risk }\end{array}$ \\
\hline $\begin{array}{l}\text { Intubation } \\
\text { Cardiopulmonary resuscitation } \\
\text { Sputum induction } \\
\text { Tracheostomy tube insertion and removal } \\
\text { Tracheostomy care, including suctioning and speaking valve } \\
\text { placement } \\
\text { Manual and non-invasive ventilation, including positive airway } \\
\text { pressure therapy (e.g., BiPAP, CPAP) or high flow nasal } \\
\text { cannula } \\
\text { Nebulization } \\
\text { Suctioning (oral; closed in-line tracheal suctioning) } \\
\text { Laryngectomy management, including voice prosthesis and } \\
\text { stoma care } \\
\text { Any manipulation of aerodigestive tract }\end{array}$ & $\begin{array}{l}\text { Classified as AGPs } \\
\text { Aerosolization of virus } \\
\text { Prolonged exposure } \\
\text { Direct contact with airway and secretions } \\
\text { Risk of reflexive sneeze/gag/throat clear/cough in response to } \\
\text { airway invasion and nasal/air irritation } \\
\text { Inability for patient to wear face mask or face covering }\end{array}$ & High \\
\hline $\begin{array}{l}\text { Transnasal procedures for evaluation or intervention of voice } \\
\text { (flexible or rigid, with or without stroboscopy) } \\
\text { Transnasal procedures for evaluation or intervention of } \\
\text { swallowing, including flexible endoscopic evaluation of swal- } \\
\text { lowing (FEES), manometry and transnasal endoscopy (TNE) } \\
\text { Nasogastric tube insertion and removal }\end{array}$ & $\begin{array}{l}\text { Close proximity to airway } \\
\text { Direct stimulation of the nasopharynx } \\
\text { Prolonged exposure } \\
\text { Risk of reflexive sneeze/gag/throat clear/cough in response to } \\
\text { airway invasion and nasal/air irritation by scope/catheter } \\
\text { Inability for patient to wear face mask or face covering }\end{array}$ & $\begin{array}{l}\text { Medium to } \\
\text { High }\end{array}$ \\
\hline $\begin{array}{l}\text { Orofacial/cranial nerve testing, including reflex testing (e.g., } \\
\text { gag reflex, cough) } \\
\text { Clinical (bedside) assessment of swallowing } \\
\text { Radiographic assessment of swallowing including barium } \\
\text { swallow study and modified barium swallow study } \\
\text { Dysphagia treatment approaches, including respiratory muscle } \\
\text { strength training }\end{array}$ & $\begin{array}{l}\text { Close proximity to airway } \\
\text { Prolonged exposure } \\
\text { Risk of reflexive sneeze/gag/throat clear/cough in response to } \\
\text { airway invasion } \\
\text { Inability for patient to wear face mask or face covering }\end{array}$ & Medium \\
\hline
\end{tabular}


for airborne transmission and requiring the use of enhanced PPE (i.e., air-purifying respirators (PAPR) or N95 masks with face shields) [22, 27-30] (Table 1).

\section{Infection Prevention and Control Recommendations}

Government and facility infection prevention and control recommendations must be sought and followed prior to commencing an AGP (Table 2). Standard precautions that apply to patients with respiratory infections, including COVID-19, consist of physical distancing, hand hygiene and PPE [2, 3, 31]. Healthcare professionals must be knowledgeable regarding COVID-19, risk for transmission, and appropriate use of PPE. When caring for a patient with suspected or known COVID-19, recommended PPE includes a PAPR or the combination of an N95, goggles or disposable face shield for eye protection, gloves, and isolation gown [3]. Employees should be provided with appropriately fitted PPE in accordance with OSHA PPE standards, and all healthcare professionals should receive training and demonstrate competency in properly donning, doffing, and disposing or disinfecting
PPE $[2,3,15,32,33]$. An AGP procedure should be deferred if adequate PPE is unavailable.

In scenarios when an AGP is indicated for a patient with confirmed or suspected COVID-19, adherence to standard and transmission-based precautions must be strictly followed [3]. Only the minimal number of essential personnel needed to perform the AGP should be present while maintaining permissible physical distancing between members during the procedure with removal of visitors, and ideally, if possible, performing the AGP in an airborne infection isolation room (AIIR). Appropriate environment and equipment decontamination should then be performed promptly after completion of the AGP [3]. Due to concern for asymptomatic carriers and a known false negative COVID-19 testing potential, some associations have recommended that endoscopy equipment should go through disinfection and the examination room be closed for approximately $1 \mathrm{~h}$ to reduce the density of SARS-CoV-2 [13].

Each patient's COVID-19 status should be determined (unknown, suspected with result pending, negative or positive test result) to assess risk for direct versus indirect treatment contact. In some areas where COVID-19 community spread is high, additional recommendations have

Table 2 Exemplars of international association's recommendations for protection and viral containment during dysphagia care [22, 23, 27-31, 37-44]

Use of aerosol-generating procedures (AGPs)

Personal protection equipment (PPE)

Decontamination

Environmental controls

Physical distancing

Use of medical aerosolizing procedures
Essential services only such that AGPs should only be performed when findings may have an immediate impact on patient management

Only with use of enhanced PPE (see below)

The most experienced provider available should perform the procedure

Limit number of people in room

Surgical masks, N95 or higher respirators

Gown and hat

Gloves

Eye protection (e.g., goggles or face shield)

Training in donning, removing and disposing of PPE

Decontaminate all surfaces and reusable equipment

Full room sanitization after all AGPs with equipment isolation for $2 \mathrm{~h}$

High level disinfection for reusable bronchoscopes, endoscopes, and manometry catheters

Single room

Ventilation without recirculation of air, or with MERV 12 filters in recirculating air systems

Triage patients and delay input where non-urgent

Physical distancing wherever possible (minimum of 6 feet)

Swallow screening by training physicians/nurses

Telehealth

Remote consultations

Limit period of time in patient's room

Avoid nebulized therapies, and instead, consider metered dose inhaler alternatives and anesthetic gels are preferred over atomized or nebulized anesthetics

Care with supplemental oxygen from all devices including nasal cannulae, face masks, venturi masks, high flow nasal oxygen and non-invasive ventilation

Use non-rebreather masks where possible

Use of filters/mesh nebulizer rather than jet nebulizer

Use negative pressure air exchange when treating high-risk patients or those known to be COVID-positive

Avoid unnecessary suctioning 
been put in place. This may include treating all patients as COVID-19 positive until proven otherwise and mandatory testing prior to the procedures [34-36]. The CDC recommends that each facility and type of practice setting completes their own risk assessment to establish guidance regarding provision of SLP services [3]. The CDC has also established Criteria for Return to Work for Healthcare Personnel with Confirmed or Suspected COVID-19 [3]. Employers should make appropriate risk assessments for their staff before permitting re-entry of employees suspected to have exposure to coronavirus into their facilities.

All the precautions and guidelines for adults are also applicable to the pediatric patients. While COVID-19 illness is relatively less prevalent in children, it can spread from care providers. Therefore, caution must be exercised with hand hygiene and strict adherence to COVID-19 precautions. Children are often in close contact with adults during feeding. Thus, anticipatory caution must be exercised even during routine care in children.

\section{Optimizing Dysphagia Assessment}

\section{Dysphagia Screening}

Reducing in-person clinical encounters and physically distancing have been advocated. While there is little evidencebase for this approach, clinicians are, in some situations, needing to delegate the hands-on portions of an exam to an alternate healthcare provider (e.g., nurse, physician) who is already in a patient's room who takes instruction from the clinician who remains outside of the room. This type of indirect approach is intended to provide recommendations to the medical team while minimizing PPE usage and overall exposure.

The benefits of dysphagia screening have been well documented in the literature for decades [45-47]. Dysphagia screening tools, such as the TOR-BSST, Modified MASA and the Yale Swallow Protocol, demonstrate excellent validity [48-50]. At present, there are no studies addressing the diagnostic accuracy of swallowing screening in patients with COVID-19. However, patients should continue to be screened by trained nurses when possible. Referrals to SLP and otolaryngology should continue in patients with COVID-19, when there are known swallowing concerns or after a failed screen. The nursing role in monitoring nutrition, hydration, and oral intake safety becomes more critical when physical distancing reduces patient contact with other healthcare professionals. Adequate nursing engagement and education by the dysphagia team merits particular emphasis at this time.

\section{Swallowing Assessment}

Once a patient with confirmed or suspected COVID-19 is referred the clinician should determine the patient's cognitive status and physical readiness to participate in an evaluation through chart review and discussion with the primary care team. For patients receiving oxygen therapy or pressure based respiratory support (e.g., BiPaP, high flow nasal cannula), efforts should be made to assure that any device covering the mouth or nasal passages can be safely adjusted or removed to allow for oral access during the swallowing assessment. Strategies may include a monitored trial of the patient's response to removal of respiratory support or using intermittent short periods of unmasked time for oral trials. This requires collaboration with the entire care team, including nursing and respiratory care. As always, it is the responsibility of the primary clinician to determine the safety of removing respiratory support, including monitoring of oxygen saturation and respiratory rate, and communicating changes observed to the entire care team.

\section{Instrumental Swallowing Procedures}

The nose and nasopharynx have been shown to hold high concentrations of SARS-CoV-2 in the early stages of the disease $[25,26,35]$. Direct stimulation of the nasopharynx and insertion and then removal of a scope from the nasal cavity has been shown to increase the risk of viral spread [25, 26, 35]. An additional consideration is the emerging evidence related to coagulation abnormalities in a proportion of patients with COVID-19, which has been associated with increased morbidity and mortality [51]. Flexible endoscopic evaluation of swallowing (FEES), transnasal endoscopy (TNE), pharyngeal-esophageal manometry and pH-MII procedures are all considered high-risk for airborne transmission. Therefore, many associations are classifying them as AGPs or potential AGPs through the pandemic [27-29, 44], and have released comprehensive recommendations on use of these procedures during the COVID-19 pandemic (Table 1). Similar recommendations have been launched for videofluoroscopy with precaution and facility-specific guidelines for transport of the patient, staff PPE, room use and room disinfection post-procedure. Local procedures should be followed (Table 2).

\section{Tracheostomy and Laryngectomy Care}

Patients with COVID-19 may have undergone tracheostomy during their intensive care unit (ICU) admission due to a need for prolonged mechanical ventilation, failed extubation or secondary to laryngeal complications. As our understanding of COVID-19 emerges, it is clear that some patients are taking longer to wean than others, with resultant increased 
incidence of ICU-acquired weakness [52]. The dysphagia team's expertise in management of swallowing and laryngeal functions is essential for tracheostomy weaning and decannulation decisions [53]. Cuff deflation trials and oneway valve trials potentially increase virus transmission by opening the tracheal airway during exhalation and increase coughing $[22,30]$. The National Tracheostomy Safety Project (2020) also recommends that in patients with confirmed or suspected COVID-19, the decision to deflate the cuff and progress respiratory weaning (including speaking valve trial) should be made in consultation with the care team, carefully weighing the benefits to the individual against the risks of the intervention to both the individual and healthcare staff [54].

In addition to tracheostomy care, otolaryngologists and SLPs also have an important role in laryngectomy care, including surgical voice restoration (SVR), prosthesis changes, and stoma care. These procedures require close proximity to the airway, and thus, are considered AGPs. Delegating tasks to those already caring for a patient is recommended. Patients with SVR prosthesis should be trained, where possible, to temporarily trouble-shoot and self-manage voice prosthesis leakages if at home [22]. It is important to note that voice prosthesis changes or open stoma inspections are considered high-risk AGPs and should only be considered if strongly indicated and only after consultation with the treating team.

\section{Rehabilitation}

During the COVID-19 pandemic, treatment of patients with oropharyngeal dysphagia should be continued. Since many dysphagia treatment techniques are classified as potential AGPs, and many facilities are limiting access to instrumental assessments of swallowing, dysphagia teams may need to provide services in less-than-ideal conditions during the pandemic that may include the need to make reasonable accommodations to continue delivery of medically necessary, skilled services to patients with dysphagia. There is an imminent need to provide effective, appropriate rehabilitation for the large volumes of patients recovering from COVID-19 to ensure they make the best possible recovery. Decisions about patients' care must be made based on current evidence and professional judgement. Prioritization of patient care for dysphagia intervention should consider the risk of a patient not receiving immediate rehabilitation on critical health outcomes (e.g., dehydration, malnutrition, risk of hospitalization, extended hospital stay).

\section{Acute care Considerations}

While considerable attention has been paid to survival rates among the rapidly increasing population of patients recovering from COVID-19, a second crisis is emerging-the challenge of managing the high disability burden associated with ICU survivorship [55]. For patients who were intubated in ICU, there may be multiple mechanisms contributing to dysphagia [56], including edema, vocal fold immobility, reduced sensation and muscle disuse. Patients who were never intubated may present similarly to patients with influenza or similar respiratory illnesses based on the symptom profile of COVID-19 [57, 58]. ICU survivors, especially those who are mechanically ventilated, often suffer from impairments in physical function, cognitive function, swallowing, and/ or emotional health collectively known as post-intensive care syndrome (PICS) [59]. These deficits may persist for months or years after a critical illness, and have substantial impact on quality of life, return to work, and disability in activities of daily living [60]. Neurologic symptoms manifest in a notable proportion of patients with COVID-19 [7]. Emerging clinical data suggest approximately $25-30 \%$ of COVID-19 survivors are presenting with new neurological impairments, including impaired consciousness, agitation and confusion, dysexecutive syndrome, acute cerebrovascular events, encephalopathy, critical illness myopathy/neuropathy and hypoxia [61]. COVID-19 is being regarded as the newest risk factor for stroke [6, 62]. Delirium may develop in up to $80 \%$ of patients in the critical care setting, and in patients with COVID-19, the prevalence of delirium is not only common, but persisting longer, likely due to prolonged use of sedatives (e.g., benzodiazepines) required for intubation. Sedatives may impair swallowing through increased pharyngeal weakness and perturbed respiratory-swallow coordination, contributing to increased risk for aspiration [63].

Patients with COVID-19 have shown a tendency to have quick respiratory status changes, for which clinicians should be vigilant. Recommendations after a clinical assessment should reflect the known instability in patients' condition in acute care settings. Patients who require ongoing respiratory support, such as oxygen therapies or non-invasive ventilation, may struggle with eating and drinking safely and meeting nutritional requirements orally. As always, patients who are on modified diets should be routinely monitored by the primary medical team, with specific attention paid to fluctuations in levels of alertness, respiratory status, and intake consumption. Removal of such compensations should be immediate once no longer needed. 


\section{Post-acute Care Considerations}

In the context of a pandemic, special considerations are required with regard to when a patient is 'ready' for transfer to rehabilitation. Ideally, patients transferred from acute care to a rehabilitation setting should have no ongoing signs or symptoms of COVID-19 infection including resolution of fever without antipyretics, documented evidence of two consecutive negative virologic specimens (i.e., nasopharyngeal swab) $24 \mathrm{~h}$ apart and a clear written plan with regard to code status [64]. Minimum criteria for safe discharge to a skilled nursing facility or home may need to be fast tracked and implemented at scale. This will require multi-stakeholder engagement, training, and cooperation. Where services are being restored in outpatient facilities, international Association guidelines recommend a staged approach as well as mechanisms for stepping services back down again if needed [56]. Maintaining active, reciprocal lines of communication between a finite number of care providers will be important for effective coordination of care, avoidance of redundancy, and unnecessary duplication of services.

Patients discharged from acute care often present with profound muscle weakness as a result of significant loss of muscle mass and disuse atrophy during critical illness. This is apparent in COVID-19 patients with multi-organ failure, multi-morbidity and prolonged lengths of stay [52]. Previously, swallowing difficulties have been demonstrated in $91 \%$ of patients who have myopathy. One-third of ARDS patients intubated for a median of 7 days have clinically important swallowing changes that persist beyond hospital discharge with 25\% taking longer than 6 months to recover [65]. Dysphagia also increases the risk of aspiration in these patients who already have a vulnerability to pneumonia, and leads to poor quality of life, further respiratory deterioration and increased mortality [66].

Dysphagia interventions in specialist rehabilitation or community settings will be essential for rehabilitation of neurogenic swallowing disorders in post-acute COVID-19 survivors [67]. Certain dysphagia therapies may also pose an increased risk of aerosol generation (e.g., respiratory muscle strength training) and should be performed by the clinician with appropriate PPE in place until a patient is deemed COVID negative [22]. The rehabilitation of COVID-19 survivors will be complex and individual patients are likely to be highly variable. A 'one size fits all' rehabilitation pathway is less than helpful, instead clinicians should aim for one that is timely, holistic and responsive to individual patient needs.

\section{Use of Telehealth}

In the context of the COVID-19 pandemic, many health professionals are facing challenges in providing care to patients using traditional in-person care. In response, organizations began advocating for telehealth or telepractice where possible to reduce unnecessary person-to-person contact [68]. Telehealth, or the use of telecommunications technologies to support long-distance clinical health care, is a model that has been used in prior public health emergencies and disasters [69], and has been implemented as part of standard care in several countries and healthcare systems prior to the current global health crisis. Indeed, prior to this pandemic, telehealth had gained momentum in a variety of disciplines, including the management of dysphagia in research and in clinical practice particularly in countries with rural and remote populations (for example, Australia) [70-83]. A growing body of literature has provided overall positive research evidence for the use of both synchronous (live interaction) and asynchronous (store and forward) telehealth to assess and treat dysphagia, mainly in adults but in some pediatric populations as well. Regarding assessments, both tele-clinical (bedside) and tele-videofluoroscopic swallowing assessments conducted remotely have been repeatedly shown to be safe, valid, and reliable when compared to traditional in-person swallowing evaluations [70-80]. In the last few years, we have also seen emerging positive research evidence for the use of telehealth for dysphagia treatment [81-83].

Despite these positive research reports, there are numerous legal, reimbursement, and licensure restrictions both within and outside the US, as well as limitations in training and telehealth infrastructure that have significantly limited the use of telehealth for dysphagia management. While there has been some temporary lifting of some of the legal and reimbursement restrictions, training and telehealth infrastructure limitations largely remain. As a result, in many settings, clinicians were asked to switch to telehealth or virtual therapy rapidly and without any preparation.

In acute care inpatient settings, clinicians reported that, in an effort to preserve PPE, they were asked to evaluate patients using a tablet or phone (video-call) or ask nurses to facilitate their evaluations while they were standing outside the patient's room. In outpatient settings, many clinics have partly or fully switched to telehealth using whatever technology is available to them and to their patients. Understandably, many clinicians have expressed feeling unprepared for this sudden shift, and many more remain apprehensive towards dysphagia tele-care mainly due to lack of physical engagement with the patient and concerns about safety and efficacy when the clinician is remotely providing care. It can be argued that providing services with heavy PPE, the use of face shields or with a plexiglass separating patient and clinician pose many of the same challenges as telehealth. Also, years of both research and clinical practice in this area show that the use of telehealth for swallowing management 


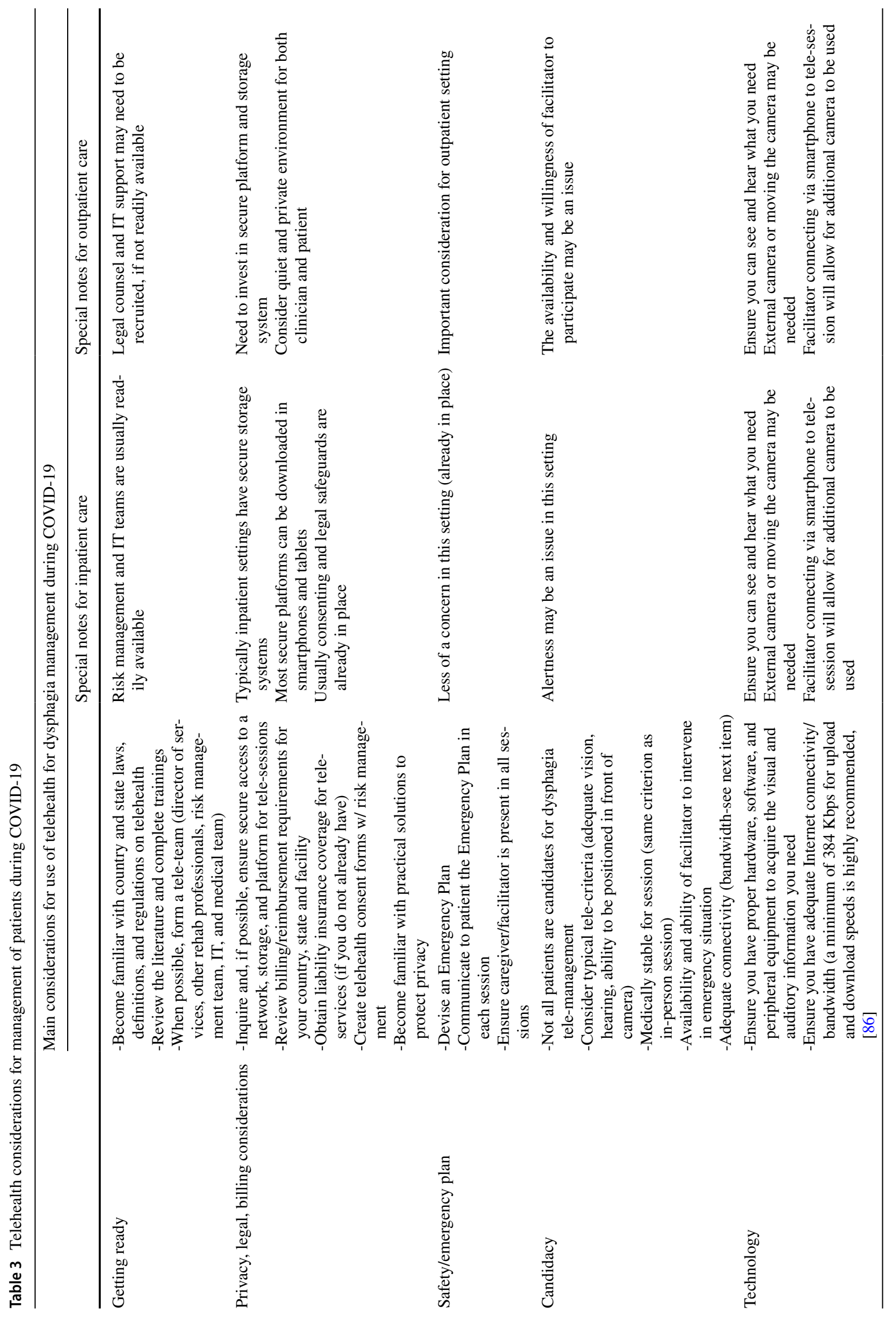




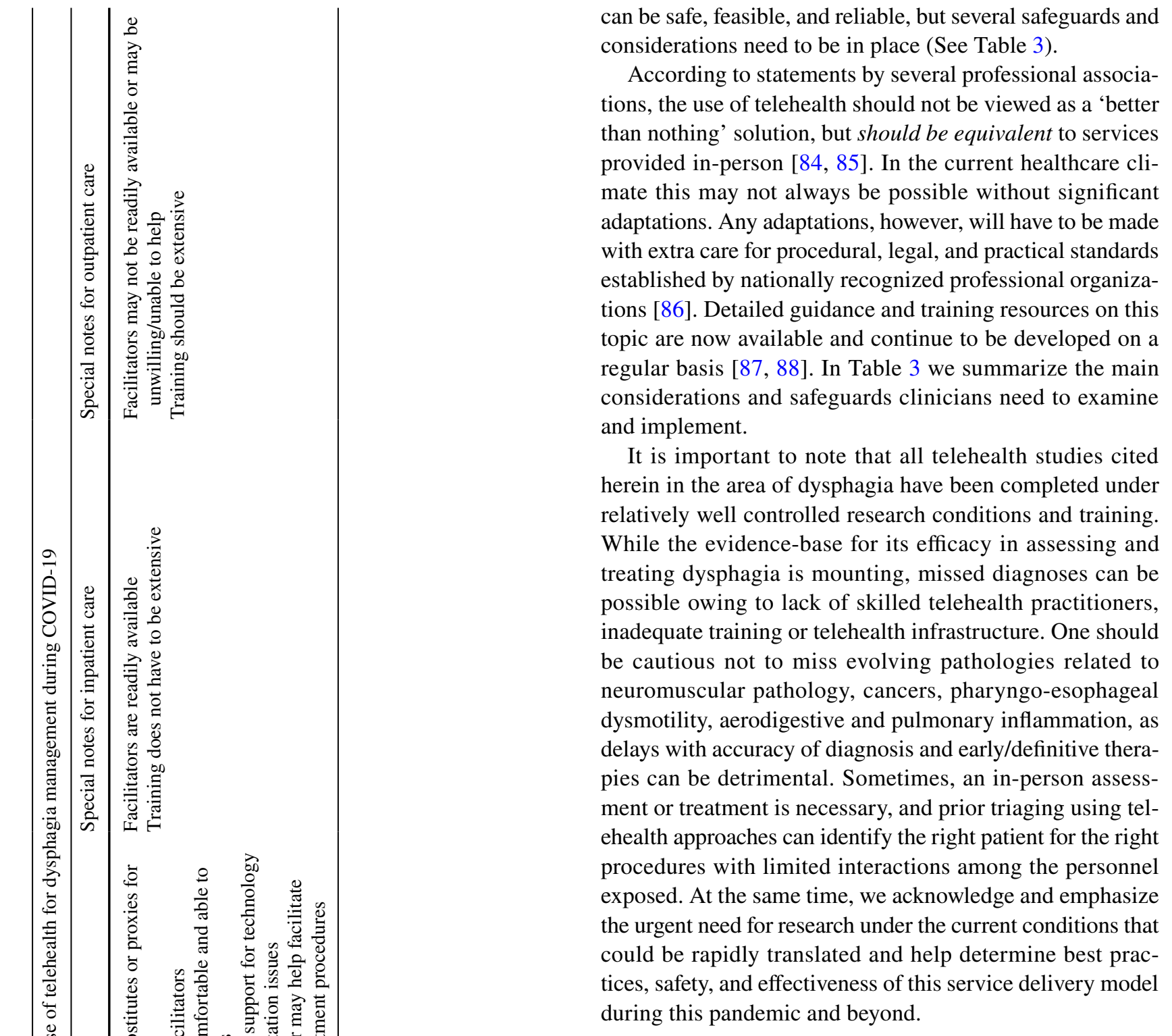

\section{Conclusion}

As the prevalence, short and long-term sequelae of COVID19 are still not firmly established, the incidence and patterns of dysphagia in these patients are uncertain. Reports from clinicians around the world suggest that dysphagia is a fairly common problem, either directly due to the trauma of intubation or secondary to respiratory damage, neurologic and cognitive deficits, deconditioning, or critical illness myopathy and neuropathy [67]. Evaluation and treatment of dysphagia falls to the specialist who may be an SLP, otolaryngologist, phoniatrician, gastroenterologist, physiatrist, or critical care physician. By definition, many of our dysphagia evaluation and treatment procedures can be considered AGPs or likely to trigger aerosol generation from patients by eliciting coughing or loud vocalizations. 
There are no evidence-based controlled trials yet published showing an increased incidence of transmission of the virus or contraction of COVID-19 in providers who evaluate or treat patients with dysphagia, but there is widespread expert consensus that our procedures place the healthcare worker at risk of infection. In the context of the available evidence on the nature of COVID-19 and how transmission is likely to occur, expert consensus has emerged on how to lessen the risk of transmission. It is strongly advised that all healthcare workers should take precautionary steps outlined above to reduce the risk of COVID-19 transmission and infection, while continuing the aforementioned dysphagia assessment and treatment procedures when indicated. Over time, as we learn how to maximize safety of transmission, these recommendations may change. For example, with rapid testing becoming more accurate and available to hospitals, patients who test negative may be evaluated within a short time of testing, with no need for extra precautions that are necessary with COVID-19 suspected or positive patients.

As patients with COVID-19 are followed and we learn more about secondary effects of the disease and stages of recovery, guidance will need to be updated. With the many uncertainties we face now, one fact is certain: the postCOVID world will not be the same as the pre-COVID world. Some dysphagia assessments and treatment sessions will likely be carried out via telehealth and new technologies that will emerge. Increasing knowledge of viral transmission of current and future diseases will likely permanently alter our way of interacting with patients, families and co-workers. Hopefully, our patients will be the biggest beneficiaries in this changing world.

Acknowledgements The Dysphagia Research Society COVID-19 Taskforce is a multidisciplinary group of academic and healthcare professionals with expertise in Speech-Language Pathology, Otolaryngology, Gastroenterology, Critical/Intensive Care, Emergency Medicine, Infectious Diseases and Respiratory Care. Our understanding and response to COVID-19 is rapidly changing, and is countryspecific depending on the local spread of COVID-19. Guidance will change over time and is dependent on new scientific evidence. This manuscript describes the current situation at the time of submission, and up-to-date information will need to be compiled as circumstances change. The Task Force has created a COVID-19 Resource Page to guide service delivery related to dysphagia management during the global COVID-19 pandemic, which can be found here. This Resource is updated weekly with the newest evidence available https://www. dysphagiaresearch.org/page/COVID-19Resources.

\section{References}

1. World Health Organization. Coronavirus disease (COVID-19) outbreak situation. 2020. https://www.who.int/emergencies/diseases/ novel-coronavirus-2019. Accessed 25 May 2020.

2. World Health Organization. Modes of transmission of virus causing COVID-19: Implications for IPC precaution recommendations. Scientific Brief. 2020. 29 March 2020. https://www.who.int/ publications-detail/modes-of-transmission-of-virus-causing-covid -19-implications-for-ipc-precaution-recommendations. Accessed 25 May 2020.

3. Centers for Disease Control and Prevention (CDC) Interim infection prevention and control recommendations for patients with suspected or confirmed coronavirus disease 2019 (COVID-19) in healthcare settings. 2020. https://www.cdc.gov/coronavirus/2019ncov/hcp/infection-control-recommendations.html. Accessed 25 May 2020.

4. Frajkova Z, Tedla M, Tedlova E, et al. (2020) Postintubation dysphagia during COVID-19 outbreak-contemporary review. Dysphagia. 2020. https://doi.org/10.1007/s00455-020-10139-6.

5. Kiekens C, Boldrini P, Andreoli A, et al. Rehabilitation and respiratory management in the acute and early post-acute phase. "Instant paper from the field" on rehabilitation answers to the Covid-19 emergency. Eur J Phys Rehabil Med. 2020. https:// doi.org/10.23736/s1973-9087.20.06305-4.

6. Helms J, Tacquard C, Severac F, Leonard-Lorant I, Ohana M, Delabranche X, Merdji H, Clere-Jehl R, Schenck M, Fagot Gandet F, Fafi-Kremer S, Castelain V, Schneider F, Grunebaum L, Angles-Cano E, Sattler L, Mertes PM, Meziani F. High risk of thrombosis in patients with severe SARS-CoV-2 infection: a multicenter prospective cohort study. Intensive Care Med. 2020. https://doi.org/10.1111/j.1365-2648.2005.03400.x.

7. Mao L, Jin H, Wang M, Hu Y, Chen S, He Q, Chang J, Hong C, Zhou Y, Wang D, Miao X, Li Y, Bo H. Neurologic manifestations of hospitalized patients with Coronavirus disease 2019 in Wuhan, China. JAMA Neurol. 2019. https://doi.org/10.1001/ jamaneurol.2020.1127.

8. Wu Y, Xu X, Chen Z, Duan J, Hashimoto K, Yang L, Liu C, Yang C. Nervous system involvement after infection with COVID-19 and other coronaviruses. Brain Behav Immun. 2020. https://doi.org/10.1016/j.bbi.2020.03.031.

9. Han Y, Yang H. The transmission and diagnosis of 2019 novel coronavirus infection disease (COVID-19): a Chinese perspective. J Med Virol. 2019. https://doi.org/10.1002/jmv.25749 PMid:32141619.

10. Pan X, Chen D, Xia Y, Wu X, Li T, Ou X, Zhou L, Liu J. Asymptomatic cases in a family cluster with SARS-CoV-2 infection. Lancet Infect Dis. 2020;20(4):410-1. https://doi. org/10.1016/S1473-3099.

11. Heinzerling A, Stuckey MJ, Scheuer T, et al. Transmission of COVID-19 to health care personnel during exposures to a hospitalized patient-Solano County, California, February 2020. MMWR Morb Mortal Wkly Rep. 2020;69:472-7.

12. Jones RM, Brosseau LM. Aerosol transmission of infectious disease. J Occup Environ Med. 2015;57(5):501-8. https://doi. org/10.1097/JOM.0000000000000448.

13. van Doremalen N, Bushmaker T, Holbrook MG, et al. Aerosol and surface stability of SARS-CoV-2 as COMPARED with SARS-CoV-1. N Eng J Med. 2020;382(16):1564-7. https://doi. org/10.1056/NEJMc2004973.

14. Centers for Disease Control and Prevention. Understanding the Difference, Surgical Mask, N95 Respirator. (2020). https:// www.cdc.gov/niosh/npptl/pdfs/UnderstandDifferenceInfographi c-508.pdf. Accessed 8 June 2020.

15. Tran K, Cimon K, Severn M, Pessoa-Silva CL, Conly J. Aerosol generating procedures and risk of transmission of acute respiratory infections to healthcare workers: a systematic review. PLoS ONE. 2012;7(4):e35797. https://doi.org/10.1371/journ al.pone.0035797.

16. Noti JD, Blachere FM, McMillen CM, Lindsley WG, Kashon ML, Slaughter DR, Beezhold DH. High humidity leads to loss of infectious influenza virus from simulated coughs. PLoS ONE. 2013;8:e57485. https://doi.org/10.1371/journal.pone.0057485. 
17. Hamner L, Dubbel P, Capron I, et al. High SARS-CoV-2 attack rate following exposure at a choir practice-Skagit County, Washington, March 2020. MMWR Morb Mortal Wkly Rep. 2020;69:606-10.

18. Chao CYH, Wan MP, Morawska L, et al. Characterization of expiration air jets and droplet size distributions immediately at the mouth opening. J Aerosol Sci. 2009;40:122-33. https://doi. org/10.1016/j.jaerosci.2008.10.003.

19. Asadi S, Wexler AS, Cappa CD, Barreda S, Bouvier NM, Ristenpart WD. Aerosol emission and superemission during human speech increase with voice loudness. Sci Rep. 2019;9:2348. https://doi.org/10.1038/s41598-019-38808-z.

20. Sandrock CE. Severe febrile respiratory illnesses as a cause of mass critical care. Respir Care. 2008;53:40-53.

21. Boswell C, Longstaff J (2020) Aerosol generating procedures (AGPs). Health Protection Scotland.

22. Bolton L, Mills C, Wallace S, Brady MC. Aerosol generating procedures, dysphagia assessment and COVID-19. Royal College of Speech \& Language Therapists. 2020. https://www.rcslt.org/-/ media/docs/Covid/RCSLT-Dysphagia-and-AGP220420FINAL-1(1).PDF?la=en\&hash=816B77BE5A88976CD97F32B84754F2 23FA761C54. Accessed 25 May 2020.

23. Evans MJ. Avoiding COVID-19: aerol guidelines. BMJ Yale. 2020. https://doi.org/10.1101/2020.05.21.20108894.

24. McGrath BA, Brenner MJ, Warrillow SJ, Pandian V, Arora A, Cameron TS, Anon JM, Hernandez Martinez G, Truog RD, Block SD, Lui GCY, McDonald C, Rassekh CH, Atkins J, Qiang L, Vergez S, Dulguerov P, Zenk J, Antonelli M, Pelosi P, Walsh BK, Ward E, Shang Y, Gasparini S, Donati A, Singer M, Openshaw PJM, Tolley N, Markel H, Feller-Kopman DJ. Tracheostomy in the COVID-19 era: global and multidisciplinary guidance. Lancet Respir Med. 2020.

25. Workman AD, Welling DB, Carter BS, et al. Endonasal instrumentation and aerosolization risk in the era of COVID-19: simulation, literature review, and proposed mitigation strategies. Int Forum Allergy Rhinol. 2020. https://doi.org/10.1002/alr.22577.

26. Zou L, Ruan F, Huang M, et al. SARS-CoV-2 viral load in upper respiratory specimens of infected patients. N Engl J Med. 2020;382:1177-9. https://doi.org/10.1056/NEJMc2001737.

27. American Speech-Language-Hearing Association. ASHA guidance to SLPs regarding aerosol generating procedures. 2020. https ://www.asha.org/SLP/healthcare/ASHA-Guidance-to-SLPs-Regar ding-Aerosol-Generating-Procedures/. Accessed 25 May 2020.

28. Bolton L, Brady G, Coffey M, Haines J, Roe J, Wallace S. Speech and language therapist-led endoscopic procedures in the COVID19 pandemic. Royal College of Speech \& Language Therapists. 2020. https://www.rcslt.org/-/media/docs/Covid/RCSLT-COVID -19-SLT-led-endoscopic-procedure-guidance_FINAL-(2). PDF $?$ la $=$ en $\&$ hash $=8101575091 \mathrm{FE} 8 \mathrm{~F} 1 \mathrm{ABA} 41 \mathrm{~B} 4 \mathrm{~B} 472387 \mathrm{D}$ AFB023A39D. Accessed 25 May 2020.

29. New Zealand Speech-Language Therapists' Association. Information regarding COVID-19. 2020. https://speechtherapy.org.nz/ info-for-slts/information-regarding-covid-19/. Accessed 25 May 2020.

30. ENT UK (2020) COVID-19. https://www.entuk.org/covid-19. Accessed 25 May 2020.

31. Chou DK, Akl EA, Duda S, Solo K, Yaacoub S, Schunemann HJ. Physical distancing, face masks, and eye protection to prevent person-to-person transmission of SARS-CoV-2 and COVID-19: a systematic review and metaanalysis. The Lancet. 2020. https:// doi.org/10.1016/S0140-6736(20)31142-9.

32. Syamal M. Literature-guided recommendations for otolaryngologists during the COVID-19 pandemic: a contemporary review. Laryngosc Invest Otolaryngol. 2020. https://doi.org/10.1002/ lio2.389.
33. Balakrishnan K, Schechtman S, Hogikyan ND, Teoh AYB, McGrath B, Brenner MJ. COVID-19 Pandemic: What every otolaryngologist-head and neck surgeon needs to know for safe airway management. Otolaryngol Head Neck Surg. 2020. https:// doi.org/10.1177/0194599820919751.

34. Rameau A, Young VN, Amin MR, Sulica L. Flexible laryngoscopy and COVID-19. Otolaryngol Head Neck Surg. 2020. https ://doi.org/10.1177/0194599820921395.

35. McGrath BA, Wallace S, Goswamy J. Laryngeal oedema associated with COVID-19 complicating airway management. Anaesthesia. 2020. https://doi.org/10.1111/anae.15092.

36. Lui RN, Wong SH, Sánchez-Luna SA, et al. Overview of guidance for endoscopy during the coronavirus disease 2019 pandemic. J Gastroenterol Hepatol. 2020;35:749-59. https://doi.org/10.1111/ jgh. 15053.

37. Ku PKM, Holsinger FC, Chan JYK, Yeung ZWC, Chan BYT, Tong MCF, Starmer HM. Management of dysphagia in the patient with head and neck cancer during COVID -19 pandemic: practical strategy. Head Neck. 2020. https://doi.org/10.1002/hed.26224.

38. Whittle JS, Pavlov I, Sacchetti AD, Atwood C, Rosenberg MS. Respiratory support for adult patients with COVID-19. JACEP Open. 2020;1:95-101. https://doi.org/10.1002/emp2.12071.

39. Speech-Language \& Audiology Canada. COVID-19 Update: Speech-language pathology services in healthcare settings during the COVID-19 pandemic. 2020. https://www.sac-oac.ca/newsevents/news/covid-19-update-speech-language-pathology-servi ces-healthcare-settings-during-covid.Accessed 25 May 2020.

40. American Academy of Otolaryngology-Head and Neck Surgery. Guidance for Return to Practice for Otolaryngology-Head and Neck Surgery 2020. https://www.entnet.org/sites/default/files /guidance_for_return_to_practice_part_1_final_050520.pdf. Accessed June 3, 2020.

41. American Academy of Otolaryngology-Head and Neck Surgery. AAO-HNS COVID-19 resources. 2020. https://www.entnet.org/ content/covid-19-resource-page. Accessed 25 May 2020.

42. Bolton L, Mills C, Wallace S, Brady MC. Aerosol generating procedures, dysphagia assessment and COVID-19: a rapid review. Int. J. Lang. Commun. Disord. 2020. https://doi.org/10.1111/14606984.12544.

43. European Centre for Disease Prevention and Control. Infection prevention and control and preparedness for COVID-19 in healthcare settings. 2020. https://www.ecdc.europa.eu/sites/default/files /documents/Infection-prevention-control-for-the-care-of-patientswith-2019-nCoV-healthcare-settings_update-31-March-2020.pdf. Accessed 25 May 2020.

44. Speech Pathology Australia. Speech Pathology Australia guidance for service delivery, clinical procedures and infection control during COVID-19 pandemic. 2020. https://www.speechpathology australia.org.au/SPAweb/About_us/COVID-19_News_and_Infor mation/COVID-19_-_Guidance_for_Service_Delivery/SPAwe b/About_Us/COVID-19/Guidance_for_Service_Delivery.

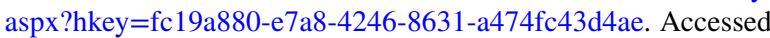
25 May 2020.

45. Speyer R. Oropharyngeal dysphagia: screening and assessment. Otolaryngol Clin North Am. 2013;46(6):989-1008.

46. O'Horo JC, Rogus-Pulia N, Garcia-Arguello L, Robbins J, Safdar N. Bedside diagnosis of dysphagia: a systematic review. J Hosp Med. 2015;10(4):256-65.

47. Brodsky MB, Suiter DM, González-Fernández M, Michtalik HJ Frymark TB, Venediktov R, Schooling T. Screening accuracy for aspiration using bedside water swallow tests: a systematic review and meta-analysis. Chest. 2016;150(1):148-63.

48. Martino R, Silver F, Teasell R, Bayley M, Nicholson G, Streiner DL, Diamant NE. The toronto bedside swallowing screening test (TOR-BSST): development and validation of a dysphagia screening tool for patients with stroke. Stroke. 2009;40(2):555-61. 
49. Suiter D, Sloggy J, Leder S. Validation of the Yale Swallow Protocol: a prospective double-blinded videofluoroscopic study. Dysphagia. 2013;29(2):199-203. https://doi.org/10.1007/s0045 5-013-9488-3.

50. Antonios N, Carnaby-Mann G, Crary M, et al. Analysis of a physician tool for evaluating dysphagia on an inpatient stroke unit: the modified Mann Assessment of Swallowing Ability. J Stroke Cerebrovasc Dis. 2010;19(1):49-57. https://doi.org/10.1016/j.jstro kecerebrovasdis.2009.03.007.

51. Levi M, Thachil J, Iba T, Levy J. Coagulation abnormalities and thrombosis in patients with COVID-19. Lancet Haematol. 2020. https://doi.org/10.1016/S2352-3026(20)30145-9.

52. RCSLT: COVID-19 speech and language therapy rehabilitation pathway. 18 May 2020. Retrieved from https ://www.rcslt.org/-/media/rcslt-covid-19-slt-rehab-pathw ay.pdf?la=en \&hash=B59AD546C6E368A34D7AA63165DC56 8C65428B2C

53. Zaga CJ, Pandian V, Brodsky MB, Wallace S, Cameron TS, Chao C, Orloff L, Atkins NE, McGrath BA, Lazarus CL, Vogel AP, Brenner MJ. Speech-language pathology guidance for tracheostomy during the COVID-19 pandemic: An international multidisciplinary perspective. Am J Speech Lang Pathol. In press.

54. National Tracheostomy Safety Project. Advice for patients with a tracheostomy in the Coronavirus pandemic. https://www. tracheostomy.org.uk/storage/files/NTSP\%2520Advice\%2520f or\%2520patients\%2520with\%2520a\%2520tracheostomy\%2520i n\%2520the\%2520Coronavirus\%2520pandemic.pdf.Accessed 25 May 2020.

55. Grabowski DC, Maddox KEJ. Postacute care preparedness for COVID-19: thinking ahead. JAMA. 2020;323(20):2007-8.

56. Macht M, Wimbish T, Bodine C, Moss M. ICU-acquired swallowing disorders. Crit Care Med. 2013;41(10):2396-405.

57. Lovato A, de Filippis C. Clinical presentation of COVID-19: A systematic review focusing on upper airway symptoms. Ear Nose Throat J. 2020. https://doi.org/10.1177/0145561320920762.

58. Richardson S, Hirsch JS, Narasimhan M, Crawford JM, McGinn T, Davidson KW, Barnaby DP, Becker LB, Chelico JD, Cohen SL, Cookingham J, Coppa K, Diefenbach MA, Dominello AJ, DuerHefele J, Falzon L, Gitlin J, Hajizadeh N, Harvin TG, Hirschwerk DA, Kim EJ, Kozel ZM, Marrast LM, Mogavero JN, Osorio GA, Qiu M, Zanos TP. Presenting characteristics, comorbidities, and outcomes among 5700 patients hospitalized with COVID-19 in the New York City area. JAMA. 2020.

59. Falvey JR, Ferrante LE. Flattening the disability curve: rehabilitation and recovery after COVID-19 infection. Heart Lung. 2020. https://doi.org/10.1016/j.hrtlng.2020.05.001.

60. Kamdar BB, Suri R, Suchyta MR, Digrande KF, Sherwood KD, Colantuoni E, Dinglas VD, Needham DM, Hopkins RO. Return to work after critical illness: a systematic review and meta-analysis. Thorax. 2020;75(1):17-27.

61. Stam H, Stucki G, Bickenbach J. Covid-19 and post intensive care syndrome: A call for action. J. Rehabilit. Med. 2020. https://doi. org/10.2340/16501977-2677.

62. Markus HS, Brainin M. COVID-19 and stroke: a global World Stroke Organization perspective. Int J Stroke. 2020. https://doi. org/10.1177/1747493020923472.

63. Cedborg AIH, Sundman E, Bodén K, Hedström HW, Kuylenstierna R, Ekberg O, Eriksson LI. Effects of morphine and midazolam on pharyngeal function, airway protection, and coordination of breathing and swallowing in healthy adults. Anesthesiology. 2015;122(6):1253-67.

64. Simpson R, Robinson L. Rehabilitation after critical illness in people with COVID-19 infection. Am J Phys Med Rehabil. 2020;99(6):470-4.

65. Brodsky MB, Huang M, Shanholtz C, Mendez-Tellez PA, Palmer JB, Colantuoni E, Needham DM. Recovery from dysphagia symptoms after oral endotracheal intubation in acute respiratory distress syndrome survivors: a 5-year longitudinal study. Ann. Am. Thorac. Soc. 2016;14(3):376-83.

66. Hafner G, Neuhuber A, Hirtenfelder S, Schmedler B, Eckel HE. FEES in intensive care unit patients. Eur Arch Otol Rhino Laryngol. 2008;265(4):441-6.

67. Gupta R, Gupta A, Ghosh AK, Stein J, Lindsay L, Beckley A, Labella AM, Tassy R, Rivera L, Rodriguez G. A Paradigm for the pandemic: a Covid-19 recovery unit. Innovat. Care Deliv. 2020. https://doi.org/10.1056/CAT.20.0238.

68. Soldatova L, Williams C, Postma GN, Falk GW, Mirza N. Virtual Dysphagia evaluation: practical guidelines for dysphagia management in the context of the COVID-19 pandemic. OtolaryngolHead Neck Surg. 2020. https://doi.org/10.1177/019459982093179 1.

69. Lurie N, Carr BG. The role of telehealth in the medical response to disasters. JAMA Intern Med. 2018;178(6):745-6. https://doi. org/10.1001/jamainternmed.2018.1314.

70. Burns CL, Ward EC, Gray A, Baker L, Cowie B, Winter N, Rusch R, Saxon R, Barnes S, Turvey J. Implementation of speech pathology telepractice services for clinical swallowing assessment: an evaluation of service outcomes, costs and consumer satisfaction. J. Telemed Telecare. 2019;25(9):545-51. https://doi. org/10.1177/1357633X19873248

71. Malandraki GA, McCullough G, He X, McWeeny E, Perlman AL. Teledynamic evaluation of oropharyngeal swallowing. J Speech Language Hear Res. 2011;54(6):1497-505. https://doi. org/10.1044/1092-4388(2011/10-0284).

72. Kantarcigil C, Sheppard JJ, Gordon AM, Friel KM, Malandraki GA. A telehealth approach to conducting clinical swallowing evaluations in children with cerebral palsy. Res Dev Disabil. 2016;55:207-17. https://doi.org/10.1016/j.ridd.2016.04.008.

73. Ward EC, Sharma S, Burns C, Theodoros D, Russell T. Validity of conducting clinical dysphagia assessments for patients with normal to mild cognitive impairment via telerehabilitation. Dysphagia. 2012;27(4):460-72. https://doi.org/10.1007/s0045 5-011-9390-9.

74. Burns CL, Ward EC, Hill AJ, Phillips N, Porter L. Conducting real-time videofluoroscopic swallow study via telepractice: a preliminary feasibility and reliability study. Dysphagia. 2016;31(3):473-83. https://doi.org/10.1007/s00455-016-9701-2.

75. Raatz M, Ward EC, Marshall J, Burns CL. Developing the system architecture for conducting synchronous paediatric feeding assessments via telepractice. J Telemed Telecare. 2019;25(9):552-8. https://doi.org/10.1177/1357633X19872091.

76. Malandraki GA, Markaki V, Georgopoulos VC, Bauer JL, Kalogeropoulos I, Nanas S. An international pilot study of asynchronous teleconsultation for oropharyngeal dysphagia. J Telemed Telecare. 2013;19(2):75-9. https://doi.org/10.1177/1357633x12 474963.

77. Kantarcigil C, Malandraki GA. First step in telehealth assessment: a randomized controlled trial to investigate the effectiveness of an electronic case history form for dysphagia. Dysphagia. 2017;32(4):548-58. https://doi.org/10.1007/s00455-017-9798-y.

78. Ward EC, Sharma S, Burns C, Theodoros D, Russell T. Managing patient factors in the assessment of swallowing via telerehabilitation. Int J Telemed Appl. 2012;2012:132719. https://doi. org/10.1155/2012/132719.

79. Ward EC, Burns CL, Theodoros DG, Russell TG. Evaluation of a clinical service model for dysphagia assessment via telerehabilitation. Int J Telemed Appl. 2013;2013:918526. https://doi. org/10.1155/2013/918526.

80. Ward E, Crombie J, Trickey M, Hill A, Theodoros D, Russell T. Assessment of communication and swallowing postlaryngectomy: a telerehabilitation trial. J Telemed Telecare. 2009;15(5):232-7. https://doi.org/10.1258/jtt.2009.081204. 
81. Burns CL, Ward EC, Hill AJ, Kularatna S, Byrnes J, Kenny LM. Randomized controlled trial of a multisite speech pathology telepractice service providing swallowing and communication intervention to patients with head and neck cancer: evaluation of service outcomes. Head Neck. 2017;39(5):932-9. https://doi. org/10.1002/hed.24706.

82. Burns CL, Wall LR. Using telepractice to support the management of head and neck cancer: key considerations for speech-language pathology service planning, establishment, and evaluation. Perspect ASHA Spec Interest Groups. 2017;2(13):139-46. https:// doi.org/10.1044/persp2.SIG13.139.

83. Malandraki GA, Roth M, Sheppard JJ. Telepractice for pediatric dysphagia: a case study. Int J Telerehabilit. 2014;6(1):3-16. https ://doi.org/10.5195/ijt.2014.6135.

84. ASHA's telepractice portal: https://www.asha.org/Practice-Porta 1/Professional-Issues/Telepractice/.

85. Krupinski EA, Antoniotti N, Brennan D, Burdick A, Cavallerano J, Li HJ, Theurer L, Winters LM, Bernard J, Linkous JD. Core operational guidelines for telehealth services involving providerpatient interactions. American Telemedicine Association. https:// www.uwyo.edu/wind/_files/docs/wytn-doc/toolkit-docs/ata_core_ provider.pdf.

86. Richmond T, Peterson C, Cason J, et al. American telemedicine association's principles for delivering telerehabilitation services. Int J Telerehabil. 2017;9(2):63-8. https://doi.org/10.5195/ ijt.2017.6232.

87. Purdue I-EAT Research Lab https://www.purdue.edu/i-eatlab/partd-citations-and-additional-resources/.

88. Speech Pathology Australia. Queensland Health e-Learning Program: Conducting Clinical Swallowing Examinations via Telepractice. 2020. https://speechpathologyaustralia.org.au/SPAwe b/Professional_Development/Telepractice/Queensland_Healt h_Program.aspx
Publisher's Note Springer Nature remains neutral with regard to jurisdictional claims in published maps and institutional affiliations.

Anna Miles PhD

Nadine P. Connor PhD, CCC-SLP

Rinki Varindani Desai MS, CCC-SLP, CBIS, CDP

Sudarshan Jadcherla MD, DCH, FRCP (Irel), AGAF

Jacqui Allen MBChB, FRACS

Martin Brodsky PhD, ScM, CCC-SLP

Kendrea L. Garand PhD, CScD, CCC-SLP, BCS-S, CBIS

Georgia A. Malandraki PhD, CCC-SLP, BCS-S

Timothy M. McCulloch MD, FACS

Marc Moss MD

Joseph Murray PhD, CCC-SLP, BCS-S

Michael Pulia MD, MS

Luis F. Riquelme $\mathrm{PhD}$, CCC-SLP, BCS-S

Susan E. Langmore PhD, CCC-SLP, BCS-S 